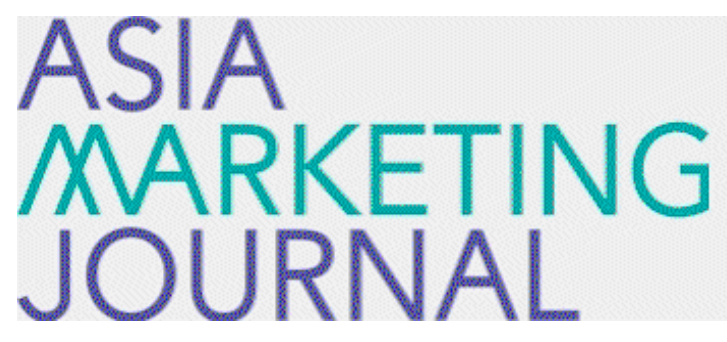

ASIA MARKETING JOURNAL

Volume 22 | Issue 4

Article 3

$1-31-2021$

\title{
Success Story: How Storytelling Contributes to BTS's Brand
}

Courtney Lazore

Follow this and additional works at: https://amj.kma.re.kr/journal

Part of the Marketing Commons

\section{Recommended Citation}

Lazore, Courtney (2021) "Success Story: How Storytelling Contributes to BTS's Brand," Asia Marketing Journal: Vol. 22 : Iss. 4 , Article 3.

Available at: https://doi.org/10.15830/amj.2020.22.4.47

This Article is brought to you for free and open access by Asia Marketing Journal. It has been accepted for inclusion in Asia Marketing Journal by an authorized editor of Asia Marketing Journal. 


\section{Success Story: \\ How Storytelling Contributes to BTS's Brand}

Courtney Lazore*

Good storytelling is at the heart of BTS as both a brand and a band. Modern brands know that story is no longer an option, but a requirement for keeping audiences engaged. With their consistent and creative reliance on story, BTS has transformed the K-Pop landscape, providing a framework for others in the industry that relies on open-structure narratives, sincerity, and active audience engagement, among other components. To investigate BTS's storytelling strategies, this article breaks down how stories permeate BTS's content, from music and videos to the Bangtan Universe and documentary films. The importance of transmedia storytelling and participatory audiences is also examined. The analysis resulted in a proposed framework that suggests the following components: 1) story as central to the brand;2) authenticity and sincerity; 3) idol participation in creative output; 4) use of transmedia storytelling and story gaps; 5) intertextuality and cohesion; 6) opportunities for audience engagement; and 7) dedicated creative staff. Utilizing this framework can help K-Pop groups elevate their brands, better use storytelling elements, and gain larger, more engaged audiences.

Keywords: BTS, storytelling, transmedia storytelling, branding strategies

\section{Statement of Intended Contribution}

This research addresses the question of "How does BTS use storytelling throughout their branding and their content?" To answer this question, I analyzed how story is used in
BTS's branding and content by looking at their brand values, lyrics, music videos, album concepts, Bangtan Universe content, and documentaries and films. From this analysis, I distilled a framework that can help others better understand BTS's strategies and potentially help other K-Pop groups better utilize storytelling methods, which should improve both their

\footnotetext{
* None/Independent Researcher (courtneymlazore@gmail.com)
} 
branding and their content, as well as the ties between the two.

Although BTS's strategies are discussed within the fandom, there has been little research formally published in this vein. This article attempts to provide a foundation for future research and discussion surrounding how BTS employs storytelling, what it means for their brand, and how others can use them as a case study to better understand these strategies. As an initial offering in this area, this article broadly contributes to brand storytelling within the realm of $\mathrm{K}$-Pop.

I believe this paper would be valuable to industry professionals who work with K-Pop groups in branding and content creation as well as anyone within a creative industry who wants to better utilize story. My goal is to encourage others to think about BTS's strategies more concretely, in the format of this framework.

\section{Introduction}

BTS's global domination caused many to question how a group of young men from a previously unknown entertainment label could reach such heights. Discussions around BTS's use of social media, their organic fandom, and the group's performance skill are commonplace. While there is no one reason for BTS's success, lying just beneath the surface of these factors is one of the core elements of BTS as both a band and a brand: good storytelling.

Although BTS's focus on storytelling is well known to fans, there has been little formal effort to analyze how story permeates throughout BTS's brand and creative strategies and how this impacts the group's brand image. In order to take a step in that direction, this paper focuses on one main question: How is storytelling utilized throughout BTS's branding and creative output? With storytelling deeply integrated into their brand as an essential component of various types of content, BTS has transformed the $\mathrm{K}$-Pop landscape, resulting in a framework for others in the industry that relies on openstructure narratives, sincerity, and active audience engagement, among other components.

This article begins with an overview of the importance of storytelling in branding and examines the usefulness of transmedia storytelling for audience engagement. Then, the article takes BTS as an exemplary case study and provides an analysis of how the group and their management company, Big Hit Entertainment, employ stories across their content in order to present a cohesive image in-line with their goals as both a band and a brand. There is then a brief comparison to the standard K-Pop model. The analysis leads to a proposed framework that would enable other Korean pop groups to better integrate storytelling into their brands, potentially resulting in larger, more engaged audiences. 


\section{Storytelling and Branding}

The importance of storytelling in branding, marketing, and business has been well documented (Denning, 2006; Herskovitz \& Crystal, 2010; Chahal, 2014; Del Rowe, 2017; Koch, Caldwell, \& DeFanti, 2019). To reach and maintain dedicated customers and build trust, brands need good stories. Well-crafted stories evoke emotions and appeal to the human mind unlike any other strategy (Woodside, 2010; Hogan, 2011). Scientific studies have shown how storytelling is "a means of making sense of the world, [a] way to make and strengthen emotional connections, and [a] way of recognizing and identifying with brands of any type" (Herskovitz \& Crystal, 2010, p. 21). Some studies in advertising have shown that stories are more effective at inciting positive emotions than purely informationbased texts (Kang, Hong, \& Hubbard, 2020). And neurological research has demonstrated that humans are simply wired to respond to stories (Zak, 2014).

Herskovitz and Crystal (2010) have argued for the necessity of "persona-focused storytelling" in branding, labeling it as "essential." The brand persona, which the authors define as "the articulated form of the brand's character and personality" is the bridge between "what a company says and what it does" (p. 21). Infusing a brand's storytelling efforts with a strong, recognizable brand persona is crucial to a successful use of story. Audiences must be able to connect with the brand's persona in order to connect with its stories. In creative industries, this is perhaps even more important, as the boundaries between brand, product, and creator blur.

\section{Transmedia Storytelling}

Transmedia storytelling is also a critical topic for creative industry brands, given the tendency for these stories to incite audience participation. One of the most important characteristics of transmedia stories is that they take place across multiple platforms and mediums, so that no singular medium has the full story. When discussing transmedia storytelling, Henry Jenkins, who coined the term, says that transmedia stories in particular can "expand the potential market for a property by creating different points of entry for different audience segments" (2007). He also explains that transmedia stories are usually not focused on one character or a singular plot-instead, there is room for many plots, sub-plots, and characters. Likewise, there are also often "gaps" in the story that audiences will try to fill in, and audience members are "drawn to master what can be known about a world which always expands beyond [their] grasp” (Jenkins, 2007). Likewise, in a book on writing technique, Donald Maass argues that 
stories should "present novelty, challenge, and/ or aesthetic value," asserting that if a creator gives readers "something to figure out," readers will be more engaged and the story will be more memorable (2016, p. 86). Creating gaps or challenges within a story is particularly useful for creative industries whose products are, at least in part, stories; transmedia stories are automatically suited for creating active audiences and generating fan engagement.

Similarly, transmedia strategies appear in branding and advertising as well. In a study of transmedia branding for World Heritage Sites in Spain, Campillo-Alhama and Martínez-Sala (2019) write that the "transmedia branding model makes it easier for brands to connect emotionally with consumers and generates communities of users around the lived and shared experience” (p. 2). They also argue that transmedia branding helps to build loyalty and that audience participation is a central component. Additionally, in a case study of how American pay-per-view channel HBO utilizes transmedia storytelling as part of its brand, Melanie Bourdaa (2014) discusses how this strategy can be used to "maintain a regular audience during the hiatuses or between episodes" which allows TV producers to "build a faithful and active audience" with fans who "help spread the media content and make it available in the public sphere" (p. 20). This was realized in the promotion of a couple of $\mathrm{HBO}$ shows, including the vampire show True Blood, where the marketing campaign involved the creation and sale of the "Tru Blood" drink that was central to the show. Blogs and documentaries were also created to showcase characters, as if they were part of the real world. Audience members were drawn in by the real-world crossovers and left to piece the information together to fill in the gaps before the start of the series. Strategies like this are indicative of the power that story and audience hold in extending, and keeping alive, any creative brand.

\section{Participatory Cultures}

Participatory culture is a concept that goes hand-in-hand with transmedia storytelling strategies, and this phenomenon often manifests around transmedia stories, given their tendency to incite active audience participation. A participatory culture is defined as having "relatively low barriers to artistic expression and civic engagement, strong support for creating and sharing one's creations, and some type of informal mentorship whereby what is known by the most experienced is passed along to novices" (Jenkins, Purushotma, Clinton, Weigel, \& Robison, 2005, p. 3). Audience members who dig through the pieces of a transmedia story and attempt to link it together, in order to contribute to the collective knowledge of the subject, is one example of participatory 
culture in action. An important result of participatory cultures is that consumers become co-creators of the media they're engaged with.

To return to the example from HBO, fans who investigated the "Tru Blood" marketing campaign and character blogs, contributing their own content to the evolving understanding of the story, were engaged in a participatory culture. Building a strong participatory culture around one's brand is a definite boon - not only are audience members engaged, but they may remain engaged even when there's no new content to work with, providing a potentially indefinite longevity for a brand or product.

\section{The Case of BTS}

Most modern brands employ at least some form of story in their branding, marketing, or even across their products, but some are clearly more effective than others. This leads to the exemplary case of BTS. How does BTS use storytelling across their branding and multimedia creative content? To explore this question, BTS's content will be considered in-depth in terms of the myriad uses of story across various types of media. Then, some key storytelling aspects will be drawn out and the impact of BTS's storytelling strategies discussed. Finally, these storytelling aspects will be used to propose a framework applicable to the larger
K-Pop industry.

When considering the case of BTS, it is imperative to realize just how integrated storytelling is within BTS as artists and as a brand. It is central and essential to who they are as an entity, and from BTS's conception, it has played a crucial role. In 2017 when BTS rebranded, the company that created the group's new designs defined the brand as "a group who is active [domestically] as well as abroad, [that] genuinely communicates their own stories" (PlusX, 2017). The new branding materials went on to say how BTS focused on a "narrative of growth" with each album release, and how this "portrait of growing youth" was a defining characteristic of the brand. The brand's core values were identified as "authentic, progressive, and bold," and a heavy focus was placed on linking BTS with their fanbase, ARMY (PlusX, 2017). Authenticity and genuine stories are the core of BTS's brand-a solid foundation upon which the group built their stories upon, with those stories later becoming a defining factor for fans of the group.

With the idea of telling stories central to their brand, BTS also uses storytelling in their work as a method for expressing brand and company values while simultaneously creating an audience based on participatory culture and engagement. Storytelling runs through their music and lyrics, their concepts, the expansive Bangtan Universe, and their docu-series and films as a common thread. These stories are a 
blend of fiction and non-fiction and rely on input from BTS as well as Big Hit's team of writers and creatives. BTS's reliance on storytelling allows them to live up to their foundational goal of telling their own stories as well as Big Hit's company slogan of "music and artists for healing."

As a musical group first and foremost, BTS's lyrics convey their sincere thoughts and emotions, something that Big Hit founder Sihyuk Bang felt was integral to the group during its conception stage. On the Korean television program Good Insight (2018), Bang stated:

Right from the start when we were making the first album with the BTS members, I asked for just one thing: That BTS's music should be stories that contain their inner selves $\cdots$ I thought it was more important than anything else that they tell their own stories.

By having the BTS members participate to varying degrees in writing lyrics, composing, and producing, the group's music captures the essence of who they are as individuals and as a group. For example, the lead single "상남자 (Boy in Luv)" from their 2014 album Skool Luv Affair expresses feelings of young love and desire, tinged with angst and performed with an aggressive slant to the sound. As a song released when the BTS members were quite young, the track is reflective of their contemporary experiences. The lead single for 2019's Map of the Soul: Persona, "작은 것들을
위한 시 (Boy with Luv)" contrasts this story with the now-adult BTS members focused on expressing a more calm, mature love that seeks harmony with the other person rather than youthful aggression. The change from in love to with love denotes both growth and story progression, as the BTS members reflected their own growth in their music's storytelling.

BTS's own stories influence their music, but they simultaneously offer widely appealing stories with an array of themes such as restless youth, society, temptation, suffering, healing, happiness, and hopefulness. These themes appear throughout their discography but are further expressed via the storylines in their music videos and conceptual timeline. The timeline traces the growth narrative outlined in their branding, moving from the school trilogy, to the youth trilogy, to the darker themes of WINGS, and finally the Love Yourself series and the Map of the Soul series. Each series focuses on a different set of themes and tells a different part of the story, but all of BTS's albums and related content contribute to the ongoing growth narrative.

The one exception to this growth narrative is the most recent album, BE. Released in November 2020, $B E$ is a reaction to the ongoing COVID-19 pandemic. While it's clear BE was not originally part of the planned storyline, BTS took the opportunity to create their most BTS-like album yet. With a heavy focus on member involvement, which speaks to their brand value of authenticity and Bang's desire 
for them to use their own tales, this album contains stories for the current state of the world. For example, lead single "Life Goes On" captures the melancholy of 2020 but provides a hopeful message of running towards the future. Another track, "내 방을 여행하는 법 (Fly To My Room)" details a story we're all familiar with by now: being stuck in one's room to the point it's suffocating, but finding a way to make it work. Despite the divergence from their ongoing narrative, BTS still made this album with story at its heart.

And it doesn't stop there. Big Hit expanded BTS's storytelling strategies with the creation of the Bangtan Universe (BU). The Bangtan Universe is a fictional storyworld that follows seven characters, with each BTS member portraying one. The characters take the real names of the members, but each has a fictional backstory and plotline. Bangtan Universe content follows these seven friends as they navigate their lives and challenges, some of which are quite dark. As such, BU content allows BTS to work in tougher themes that don't have a place in their musical work. For example, some characters are plagued by abusive families, severe poverty, mental illness, abandonment, and suicidal ideation. While some themes overlap with the stories expressed through their album concepts, such as the growing pains of youth, friendship, and overcoming challenges, the ability to work in other types of stories creates more opportunities for audience engagement.
Additionally, BU content also branched off into transmedia storytelling, as bits of the narrative can be found across many sources, with no one source presenting the comprehensive story. BU content exists in some music videos, additional online content videos, a webtoon, a blog, a mobile game, and books published by Big Hit Entertainment. The fragmented nature of the story requires the audience to piece it together in order to gain a fuller understanding, which in turn helped create a strong participatory culture within the audience. Even prior to the official use of the BU logo to signify storyworld content, fans were creating theories about music videos and stage performances, searching for hidden clues and posting about them on social media, a practice that continues to this day as more BU content is periodically released.

Storytelling can also be found in the docuseries and films Big Hit has released that chronicle several of BTS's tours. These endeavors directly align with BTS's core of telling their own stories, as the docu-series focus on the members' personal thoughts and feelings while the overarching story of the group and their fanbase is reinforced. There are currently three docu-series with film counter-parts: Burn the Stage, Bring the Soul, and Break the Silence. Taking the first docu-series, Burn the Stage, as an example, the BTS members speak in interviews about struggles faced either on tour or in their careers, which is spliced together with various behind-the-scenes moments. The 
film version follows a more structured storyline, emphasizing the group's journey and growth during their WINGS tour. However, both versions of Burn the Stage allow BTS to tell more of their real, sincere stories, which also serves to humanize the group to their fans and further their brand image of authenticity.

\subsection{Key Storytelling Aspects}

It's clear that storytelling is pervasive for BTS, and by considering how the band utilizes this tool as an extension of their brand, there are several key characteristics we can extract from BTS's case. First, their stories are based on authenticity and sincerity. Bang made this clear in his creation of the band, and it is something many fans identify when asked what's special about BTS. The frequency that terms like authentic, genuine, and sincere come up in conversations with fans stands as testament to the group's (and the label's) success in communicating those values.

Another key characteristic is artist input and self-creation, which goes together with authenticity. Rather than writing a few lyrics here and there or producing a couple of songs, the BTS members are deeply involved in conversations about what they want to create and what messages they want to send, in addition to the lyric writing, composing, and production that each member participate in (Herman, 2017). BTS member RM is known for posting in-depth behind-the-scenes videos on the VLIVE platform after album releases. In these videos, he explains how each song was created and how other members were involved. These videos, done of his own volition, also help reinforce the group's authenticity to fans.

Transmedia storytelling is also a major element. This is mainly accomplished with Bangtan Universe content. Transmedia stories lend themselves to being fragmentary in nature, and making a transmedia story creates many more points of entry for audience members. This inspires a participatory culture and active engagement as the audience discusses the story and attempts to put the pieces together, usually through collective knowledge.

The next aspects are cohesiveness and intertextuality. BTS's stories, despite being fragmented, are cohesive and rely on a great degree of intertextuality - which explains how stories refer to and influence each other, often affecting how audiences perceive them. Themes, images, and specific phrases appear at different moments in BTS's stories, whether it's in their music, videos, BU content, or films. Even live performance stages sometimes contain hints or clues that tie to past and upcoming releases, and recurring images are often utilized, such as the desert and the sea. Intertextuality also occurs with texts outside of BTS, such as the WINGS album's references to Hermann Hesse's novel Demian and the song "Spring Day," which references Ursula K. Le Guin's short 
story, "The Ones Who Walk Away From Omelas." There are additional ties to Carl Jung's psychoanalytical ideas, as presented in Murray Stein's book, Jung's Map of the Soul, and Erich Fromm's ideas of self-love, found in his text titled The Art of Loving. Intertextuality deepens the web of content for audiences, creating more opportunities for them to engage and respond.

Finally, BTS's stories rely on universal themes and relatable characters. Themes that are widely applicable, such as the growing pains of youth, temptation, and hopefulness draw in a larger audience that can empathize with the characters, and using characters that are regular people, rather than superheroes, can also increase the audience's investment in the story as they can relate to what is being portrayed more closely.

Storytelling manifests in most of BTS's work and is thus pushed to the forefront of their brand strategy - by leaning heavily on good storytelling, BTS builds interest and engagement for their brand while making emotional connections to the audience as artists. What results is a deeply dedicated fanbase that actively participates in making content, helping to promote the band even further.

\subsection{Comparison With Other K-Pop Models}

The K-Pop model for finding, training, debuting, and marketing $\mathrm{K}$-Pop groups has been fairly standardized in the modern industry, though there are some variations. One study suggested that K-Pop's global success is due to four main elements: "preparation, delivery, consumers, and content” (Seo, 2012). Aspiring idols are located via open auditions, survival shows, or street casting and are trained rigorously, often for multiple years. Trainees learn “singing and dancing but also acting, foreign language skills and personal development" and must pass evaluations (Seo, 2012). A heavy focus is placed on gathering "creative input" from "experts in many countries and in multiple industries, and music and performances focus on many Westernstyle pop conventions, difficult choreographies, and a range of styles, which keeps performers "fresh and appealing" (Seo, 2012). Marketing relies heavily on localization, a process where music and performances are targeted to specific overseas audiences (such as Japan or the U.S.), and social media plays a big role in garnering a global audience. Many fans create their own K-Pop content, such as dance covers, reaction videos, and tutorials, and upload them to social media, which further markets the group to other audiences.

BTS is no exception to this K-Pop model. But where they differ is in their focus and implementation of the "content" element. K-Pop groups rely on concepts for each album, but many albums are self-contained stories or narratives limited to a music video. A few groups release album trilogies, such as GOT 7's Flight Log series or MONSTA X's The Clan 
series. While these trilogies seek to tell stories, they are usually contained to the world of the album and its promotional video content. LOONA and EXO are two additional examples of more in-depth storytelling in K-Pop, but their story content is limited to their videos and based less in realistic or relatable stories. And while there are now more K-Pop artists participating in songwriting and giving creative input in other creative areas than in previous generations, participation is not fully consistent.

On the other hand, BTS's focus is on making their content all relate back to their storieswhether that's their album concepts, lyrics, or additional content. They consistently participate in song and lyric writing, give input for concepts, and work together with their creative team to thematically link all of their work together. BTS's long list of accolades and unparalleled social media engagement are testament to their success at operationalizing stories as engagement tools, which has thus far exceeded that of any other $\mathrm{K}$-Pop idol. The various strategies for integrating authentic storytelling into K-Pop is highly underutilized by much of the industry.

\subsection{Impact and Implications Of BTS's Storytelling}

Now the question is: what is the impact of BTS's storytelling, and what can K-Pop learn from BTS? First, it is clear that BTS has a highly engaged audience (with a participatory culture), thanks in part to their strategic use of story. Rather than relying on creative expression towards a passive audience, their stories drive engagement and active participation. Part of this engagement is tied to the transmedia, fragmentary nature of the stories that utilize intertextuality. One can easily find numerous discussion posts, tweets, and videos with in-depth deliberations about BTS's stories and concepts. There are entire Twitter accounts and websites dedicated to analyzing and connecting BTS's stories, such as the ARMY Theorists Society ( @ ARMY_society) account on Twitter, which currently has over 51,000 followers. Theory posts are also popular enough to have their own flair tag on the BTS subreddit.

The vast amount of fan-created works that react to or analyze BTS's stories found on YouTube illustrates something Dr. Jiyoung Lee calls the "network-image" in her book on BTS and philosophy, which is indicative of the success of BTS's strategy. The network-image "does not pursue the traditional art values such as 'truth,' 'contemplation,' or 'the beauty of supremacy.' The social role expected of the network-image is "sharing value"” (Lee, 2019, p. 117). And sharing value is a goal that any brand, creative or otherwise, aspires to. Lee also argues that this art form "is tearing down the existing boundaries between media forms and between the artist and the receiver, forming a new territory" (p. 117). This argument ties back to the previously established ideas of 
participatory cultures and intertextuality. Fans participate in reacting to, recreating, or analyzing BTS's content, which they then share online to connect with other fans and contribute to the fandom's collective knowledge. These activities, empowered by the destruction of boundaries that allows anyone to become a creator, is one of the most visible evidences of BTS's success and a lesson that can be learned by others in the industry. Transmedia stories, stories with symbols and motifs, and intertextuality all create space for audience members to become producers and contribute to the network-image.

\section{Proposed Framework For Integrating Storytelling Into $\mathrm{K}-\mathrm{Pop}$}

From BTS's innovative use of storytelling strategies and creative outputs, it is possible to derive a framework that has helped BTS inspire a deeply connected and engaged audience. To be sure, $\mathrm{K}$-Pop is not devoid of storytelling, but few have a brand strategy that connects story to the core of the brand. A few groups use stories to create thematic connections between albums, but these often rely on supernatural or fantasy stories, rather than everyday people as characters.

K-Pop albums are often concept-based, which can be fertile ground for a better use of storytelling. While the idea of the concept album has been around for decades in the West, the term usually refers to albums that are linked via their use of thematically similar lyrics or a consistent sound. Some Western artists have taken the idea further, with themed albums that revolve around a story, such as My Chemical Romance's The Black Parade, where the band's styling and theatrical music videos contributed further to the album's concepts. But these albums are often self-containedtheir stories end with the last song. Modern K-Pop albums, however, have truly brought the idea of a "concept album" to life. As an industry, K-Pop is uniquely suited for a more focused use of story. Given the industry's heavy reliance on album concepts, themes, costuming, elaborate performances, high-production videos, and theatrics, which are often all interconnected, a framework inspired by BTS can help K-Pop artists better integrate story into their core identities and reach and maintain larger, more engaged audiences.

To develop a useful framework, I analyzed each of the major areas where storytelling manifests within BTS's branding and content (music videos, album concepts, the Bangtan Universe, and movies and docu-series) to determine the main recurring themes and strategies. I also relied on interviews and comments from the BTS members, Big Hit's CEO Sihyuk Bang, and others. The result was an initial framework of seven main elements: 
centrality of story to brand and content, authentic and sincere stories connected to group identity, idol participation in music and/ or concept creation, transmedia storytelling, space for audience participation, intertextuality and cohesiveness, and a dedicated creative staff. Each of these elements is outlined below with brief explanations tied to the case of BTS.

First, story must be central in some way to brand identity as well as content. Music and performance are hugely important, but without story, something will always be lacking. Youngdae Kim, a music critic who has followed BTS's activities for many years, noted that "BTS place narratives at the center of their career, and they are the only K-Pop artists to do so" (Kim, 2019a). Both the BTS members and CEO Bang reinforce this idea, as they have reiterated numerous times the centrality of story to BTS as an entity (Bruner, 2018; Big Hit Labels, 2019; Dispatch Magazine, 2018; Kang, 2020). Stories are the glue that binds everything together; when stripped down to their bare elements, songs, music videos, and performances should all rely on some sort of story, which in turn feeds into the artist's brand.

Second, the storytelling should be authentic, sincere, and connected to the group's identity to prevent potential rejection from the audience. "Authenticity" and "sincerity" are terms that commonly appear when both BTS and fans speak about their involvement with their work. Member RM has credited their sincerity as part of their success (Hong, 2020). "I think audiences today are smart and sophisticated. They can tell right away what is genuine and what is not," he said in one interview (Suh, 2019). At a press conference about their album BE, Jungkook commented that he wanted to express "sincerity and authenticity" with the title track "Life Goes On” (Collucci, 2020). Similarly, CEO Bang has emphasized how important sincerity and authentic storytelling is (Bruner, 2019). One article recalled how Bang "encouraged [the BTS members] to delve into themselves and find their own stories"; even when the members were trainees, he'd ask, “’Don't you have anything you want to say?”' (Suh, 2019). Docu-series and films like Break The Silence: Persona, where the BTS members have space to speak self-reflectively, also contributes to the group's authenticity (Park, 2020). Some also credit BTS’s success in America in part to their authenticity, given the value of an authentic narrative in that market (Kim, 2019b). Valuing K-Pop idol input when it comes to album concepts and messages is crucial for maintaining the authentic appeal to audiences.

Hand in hand with authenticity, the freedom for idols to participate in the creation of songs, videos, story plans, and other content is also necessary. BTS is well known for their participation in writing lyrics and composing songs, and member RM often provides behind-the-scenes videos on the VLIVE app where he discusses how each song on an album came together. In 
interviews, the group discusses how they work as collaborators with Big Hit's production team, rather than operating in a hierarchical model where material is handed down to the group (Ochoa, 2020; Calixto, 2018). Group members are also known to give their input in the creative concepts and storylines that go together with their albums (Herman, 2017). By allowing performers to contribute some of their own stories, artists can project a more authentic image that will resonate more deeply with audiences.

Additionally, transmedia strategy should be employed where possible. There are countless ways to creatively construct a story across multiple mediums, and there are opportunities for multiple characters and plots, allowing each member of a K-Pop group to be featured. Creating multiple entry points for audiences will ensure a group's narrative is optimized for success. Story gaps are also an important part of the framework, because without something for the audience to figure out, there will be fewer opportunities to create a participatory culture. BTS's content exemplifies this transmedia strategy most notably in the Bangtan Universe content, which is available across many platforms and leaves spaces for fan input and interpretation. Each member is represented by a fictional character, creating endless possibilities for storylines, and fans congregate in droves online to discuss, analyze, and solve the puzzle of the story. Many fans contribute elaborate Twitter threads on accounts like the ARMY Theorists
Society (@ARMY_society) or produce YouTube videos or websites that analyze the minute details of each story, all of which demonstrate the power of this strategy.

In the same vein, a clever use of intertextuality and cohesive stories are also critical, as this inspires more audience engagement and gives fans reasons to cycle back through older content. Drawing inspiration from and making references to works outside of the main story may also be of use. Much of BTS's content refers to other BTS content-sometimes it's because the storylines are connected, and sometimes it's just a fun Easter egg. Either way, this practice leads many fans to interact more with BTS's content library. Dr. Jiyoung Lee notes how CEO Bang would "plan meticulously for years, planting seeds one by one. When fans eventually connect the dots, they feel electrified" (Kang, 2020). This level of engagement in the story is one of the main goals of this framework.

Finally, having dedicated creative staff to plan storytelling ventures is necessary. Without support at the level of the company or label, it is unlikely $\mathrm{K}$-Pop groups can achieve this framework successfully. BTS is well-supported by Big Hit staff members and other creatives who work together to create concepts, Bangtan Universe content, and album narratives. While BTS works in collaboration with their team, a dedicated creative team provides the foundation for bringing everything to life. CEO Bang, writers, directors, and others all work together 
to help BTS tell their stories (Kang 2020; Herman, 2017). While it's important that stories come from the artist and be portrayed as genuinely as possible, the onus cannot rest on the idol alone.

\section{Conclusion}

In creative industries, stories can be deeply integrated into the brand, product, and creator. In this sense, story serves both as a product that audiences interact with and react to, and as something deeply associated with a brand (or a band). In a way, story is BTS's brand, and the brilliance of their storytelling lies in its open, far-reaching structure and its adherence to key aspects that create engaged audiences through social media, participatory culture, and the network-image. This framework can be applied widely in the K-Pop industry to improve audience engagement and connection. BTS's stories are part of their creative product, but that doesn't make them any less effective as a part of their brand strategy.

Although BTS's use of storytelling is effective and well done, there are a couple of areas for potential improvement. The current Bangtan Universe storyline began with the HYYH era in 2015 and has yet to fully resolve. There's lots for fans to work with, but spinning a story over such a long time period leaves room for potential plot holes, retconning, and other unsatisfactory resolutions. It would be good to resolve this storyline and move forward with either a new storyline or at least a new "chapter" in the story, keeping the content fresh. Additionally, much of the story takes place in the text of the HYYH Notes, published in albums and books. This is a great way to provide more of the story, but since the texts are written as diary entries from each character, the writing can at times be dry. Striking more of a balance between video content and written content may help alleviate this minor problem. Beyond BU content, BTS's elements of authentic and sincere storytelling could be further reinforced with commentary or behind-the-scenes style videos from other members. While member RM often gives this insight (and it's very valuable to fans and their brand alike), additional input from other members can help strengthen their strategy even further.

While I have attempted to distill important aspects of BTS's use of storytelling into a digestible framework, this is an initial step in the process of better understanding the importance of storytelling in K-Pop and should not be taken as static. Rather, this is something that can be further built upon over time as the industry continues to change and innovate. Given BTS's massive success over the last few years, they will remain an exemplary case that can serve as a model for future K-Pop groups, leading to insights that can help elevate brand 
image and solidify a loyal, dedicated audience.

〈Received December 14. 2020〉

〈Accepted January 25. 2021〉

\section{References}

BangtanSubs (2018), Good insight season 2 , [Video]. Daily Motion. https://www. dailymotion.com/video/x6y2b23.

Big Hit Labels. (2019, August 25). Big hit corporate briefing with the community $(2 \mathrm{H}$ 2019) [Video]. YouTube. https://www. youtube.com/watch? $\mathrm{v}=$ IGI3y YhzDfc \&ab _channel $=$ BigHitLabels

Bourdaa, Melanie (2014), "This is not Marketing. This is HBO: Branding HBO with Transmedia Storytelling," Networking Knowledge: Journal of the MeCCSA Postgraduate Network, 7(1), 18-25.

Bruner, R. (2018), "BTS: Taking K-pop Worldwide," TIME, (October 22), 44-45. Bruner, R. (2019), "The Mastermind Behind BTS Opens UP About Making a K-Pop Juggernaut," (accessed January 22, 2021), https://time.com/5681494/bts-bang-sihyuk-interview/

Campillo-Alhama, Concepción and Alba-María Martínez-Sala (2019), "Events 2.0 in the Transmedia Branding Strategy of World Cultural Heritage Sites," El Profesional de la Información, 28(5), 1-15.
Calixto, J. (2018). "BTS on Why Their Music Speaks to Young People and Their Collaborative Creative Process," (accessed January 23, 2021), http://www.mtv.com/ news/3099373/bts-grammy-museumconversation-recap-quotes/

Chahal, M. (2014), "The Top Storytelling Brands," (accessed December 14, 2020), https://www.marketingweek.com/thetop-storytelling-brands.

Collucci, R. (2020), "A Message of Comfort and Healing: Here is What BTS Had to Say About Their New Album Be." (accessed January 22, 2021), https://thehoneypop. com/2020/11/20/a-message-of-comfortand-healing-bts-new-album-be/

Del Rowe, Sam (2017), "Marketing Needs a Story to Tell," CRM Magazine, 21(2), 2023.

Denning, Stephen (2006), "Effective Storytelling: Strategic Business Narrative Techniques," Strategy \& Leadership, 34(1), 42-48.

Dispatch Magazine (2018), "Dicon: Behind BTS," 2, 113-121.

Herman, T. (2017), “BTS' Creative Team Discusses Group's Artistic Narrative," (accessed December 14, 2020), https://www. billboard.com/articles/columns/k-town/ 7981991/bts-creative-big-hit-entertainment -interview.

Herskovitz, Stephen and Malcolm Crystal (2010), "The Essential Brand Persona: Storytelling and Branding," Journal of Business Strategy, 
31(2), 21-28.

Hogan, Patrick (2011), Affective Narratology:

The Emotional Structure of Stories. Lincoln:

University of Nebraska Press.

Hong, Dam-young (2020), "'Our Sincerity Has Overcome Language and Race," (accessed January 22, 2021), http://www.koreaherald. $\mathrm{com} /$ view.php? ud = 20200911000543

Jenkins, Henry (2007), “Transmedia Storytelling 101," (accessed December 14, 2020), http:// henryjenkins.org/2007/03/transmedia storytelling_101.html.

Jenkins, Henry, Ravi Purushotma, Katherine Clinton, Margaret Weigel, and Alice Robison (2005), "Confronting the Challenges of Participatory Culture: Media Education for the $21^{\text {st }}$ Century," white paper, MacArthur Foundation.

Kang, Haeryun (2020). “'Hitman’ Bang Si-hyuk, The Brand-New Billionaire Behind BTS," (accessed January 22, 2021), https://www. npr.org/2020/11/18/935848354/hitmanbang-si-hyuk-the-brand-new-billionairebehind-bts

Kang, Jin-ae, Sookyeong Hong, and Glenn Hubbard (2020), "The Role of Storytelling in Advertising: Consumer Emotion, Narrative Engagement Level, and Word-of-Mouth Intention," Journal of Consumer Behavior, 19(1), 47-56.

Kim, Y. (2019a), "Authentic Message of Their Own Narrative," Koreana, 33(3), 13-17.

Kim, Youngdae (2019b), BTS The Review,
South Korea: RH Korea Co.

Koch, Leah, Helen Caldwell, and Mark DeFanti (2019), “Using Brand Storytelling to Gain Competitive Advantage in Higher Education Marketing," Competition Forum; Indiana, 17(1), 28-35.

Lee, Jiyoung (2019), BTS: Art Revolution: BTS Meets Deleuze, South Korea: Parrhesia. Maass, Donald (2016), The Emotional Craft of Fiction: How to Write the Story Beneath the Surface, Cincinnati: Writer's Digest Books.

Ochoa, J. (2020). “BTS Talk New Album 'Map of The Soul: 7': 'The Genre is BTS,'” (accessed January 23, 2021). https://www. grammy.com/grammys/news/bts-talknew-album-map-soul-7-genre-bts

Park, J. (Director). (2020). Break the Silence: Persona [Film]. Big Hit Three Sixty.

PlusX (2017), "BTS Brand Experience Design Renewal,” (accessed December 14, 2020), https://www.behance.net/gallery/55324473 /BTS-Brand-eXperience-Design-Renewal. Seo, Min-soo (2012), “Lessons from K-Pop's Global Success," SERI Quarterly, 5(3), 60-66.

Suh, B. (2019), "From Idol to Artist," Koreana, 33(3), 6-11.

Zak, Paul (2014), "Why Your Brain Loves Good Storytelling," (accessed December 14, 2020), https://hbr.org/2014/10/why-your-brain -loves-good-storytelling. 